\title{
Analisis Perbandingan Brand Equity Samsung dan LG
}

\author{
Imam Arif Fikri ${ }^{1 *}$, Lina Ariyani ${ }^{2}$, Jenji Gunaedi Argo ${ }^{3}$ \\ ${ }^{123}$ Universitas Pembangunan Nasional Veteran Jakarta, Indonesia \\ Author E-mail: Imamarif@upnvj.ac.id
}

\begin{abstract}
A B S T R A K
Penelitian ini merupakan penelitian kuantitatif yang bertujuan untuk mengetahui perbandingan brand association, perceived quality, dan brand loyalty terhadap brand equity pada perusahaan Samsung dengan LG di wilayah Jakarta Selatan. Penelitian ini menggunakan 100 responden sebagai sampel dengan metode purposive sampling. Teknik analisis dalam penelitian ini menggunakan Uji Independent Sample T Test dengan menggunakan SPSS 26. Hasil penelitian ini menunjukan bahwa (1) Brand Association Samsung lebih unggul dari LG, (2) Perceived Quality Samsung lebih unggul dari LG, (3) Brand Loyalty Samsung lebih unggul dari LG.
\end{abstract}

Kata Kunci: Brand Equity, Brand Association, Perceived Quality, Brand Loyalty.

\section{A B S T R A C T}

This research is quantitative study that aims to compare brand association, perceived quality, and brand loyalty to brand equity in Samsung and LG companies in the South Jakarta area. This research used 100 respondents as a sample with purposive sampling method. The analysis technique in this study uses the Independent Sample T Test using SPSS 26. The results of this study indicate that (1) Samsung Brand Association is superior to LG, (2) Samsung's Perceived Qualty is superior to LG, (3) Samsung's Brand Loyalty is superior to LG. superior to LG.

Key word: Brand Equity; Brand Association; Perceived Quality; Brand Loyalty.

Copyright $\odot 2021$ Authors. This is an open access article distributed under the Creative Commons Attribution License, which permits unrestricted use, distribution, and reproduction in any medium, provided the original work is properly cited.

\section{PENDAHULUAN}

Persaingan di dalam dunia bisnis electronic semakin hari kian meningkat, kondisi yang seperti ini menuntut produsen semakin berinovasi dalam membuat produknya dan mempertahankan konsumennya. Era ini dimulai dengan semakin menjamurnya produk-produk maupun jasa yang berinovasi. Salah satu produk yang mengalami perkembangan adalah bidang elektronik dan teknologi, yang disebabkan meningkatnya keperluan dan kebutuhan masyarakat di bidang tersebut. Hal ini dimengerti oleh produsen asal 
negeri gingseng yaitu LG dan SAMSUNG yang memproduksi produk elektronik seperti televisi, Home Theater, Air Conditioner, kulkas, dan lain sebagainya. Dalam hal ini kedua produsen tersebut bersaing untuk mendapatkan hati di para konsumennya, yaitu dengan memperkuat ekuitas merek atau brand equity di benak konsumen.

Situasi persaingan pasar sekarang menjadi meningkat dikarenakan adanya persaingan yang ketat dan meningkat diantara para produsen. Kondisi pasar saat ini telah dibanjiri oleh bebagai macam barang produksi yang di produksi dalam jumlah yang banyak, yang menbuat konsumen mempunyai pilihan yang banyak terhadap produk. Persaingan perusahaan bukan saja merebutkan konsumen saja, akan tetapi dapat dikaitkan dengan dengan adanya merek yang mampu memberikan gambaran khusus bagi pemakainya (Putri \& Gede, 2018).

Semakin meningkatnya kebutuhan yang ada dimasyarakat akan barang elektronik, maka dapat menimbulkan pemenuhan kebutuhan masyarakat mengenai hal itu, yang artinya usaha dalam menciptakan barang elektronik tersebut, dan akan ditandai dengan banyaknya produsen produk elektronik. Produk elektronik buatan
Korea Selatan banyak diminati dikarenakan Korea Selatan adalah negara pembuat plasma terbesar di dunia (Jauhari, 2020).

Menurut data Kementrian Perindustrian menunjukan pada kuartal III/2019, pada industri computer, barang elektronik, dan optic bertumbuh 5,75\%. Pada dua kuartal sebelumnya kinerja sector tersebut mengalami penurunan sebesar $18,50 \%$ pada kuartal pertama dan $4,14 \%$ pada kuartal kedua. Dari data kinerja diatas ditopang oleh perindustrian kecil dan menengah yang saat periode tersebut tumbuh di angka $24,36 \%$. Sedangkan industry besar dan sedang mengalami penurunan sebesar 5,39\% (Oktaviano, 2019). Dengan demikian berdasarkan dari data yang dikeluarkan oleh TOP BRAND menunjukan bahwa persaingan yang cukup ketat antara brand LG dan Samsung, berikut adalah data TOP BRAND 2020:

Dari gambar diatas dapat dilihat bahwa Samsung mendapatkan $24,40 \%$ sedangkan LG $14,10 \%$ di bidang Home Theater, sedangkan dibidang lemari es LG mengungguli Samsung dengan perolehan point $20,70 \%$ sedangkan Samung mendapatkan $8,80 \%$ saja, kemudian dibidang televisi $L C D$ kedua brand tersebut hampir seimbang yaitu dengan perolehan point LG $18,80 \%$ sedangkan

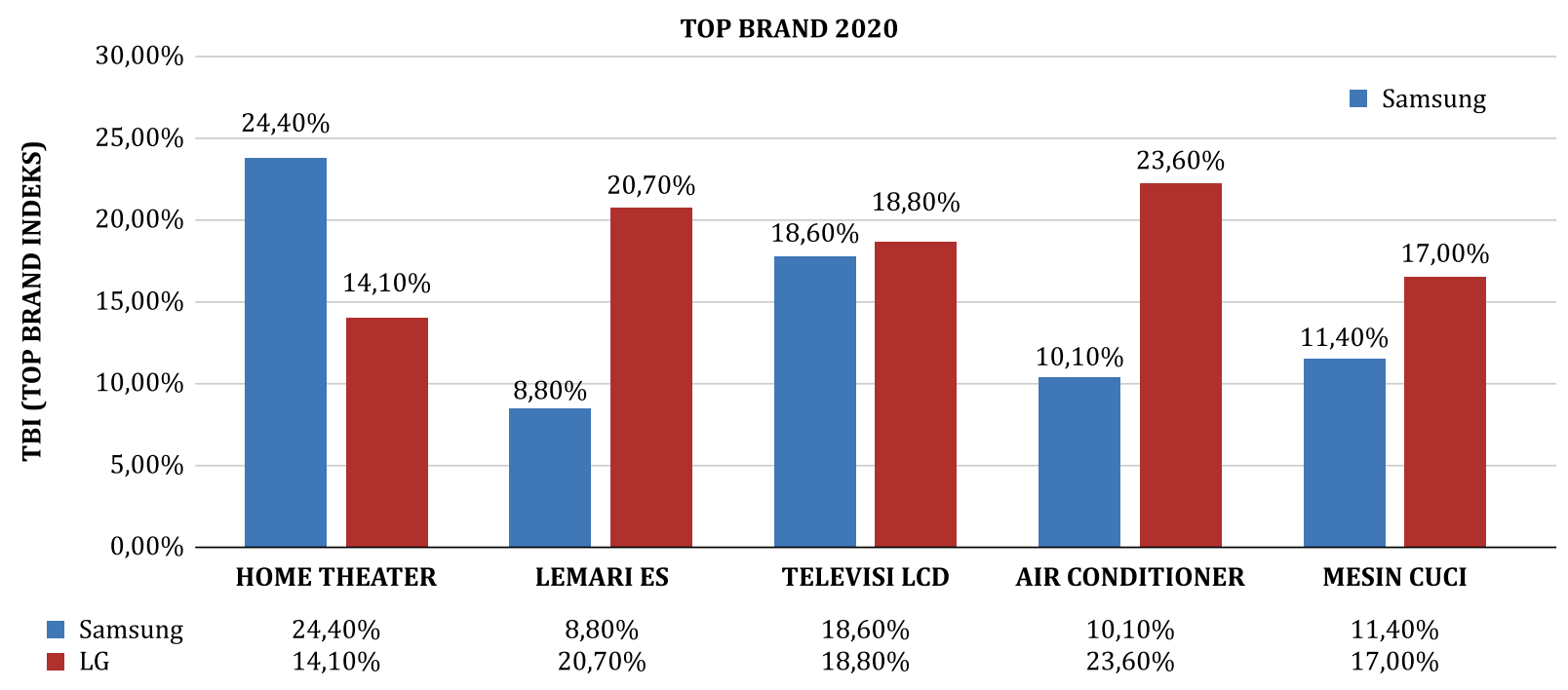

Gambar 1. Top Brand Index 2020

Sumber : Data diolah (2021) 
Samsung 18,60\%, kemudian di bidang Air Conditioner LG menungguli Samsung dengan telak di point $23,60 \%$ sedangkan Samsung hanya mendapatkan $10,10 \%$ saja, dan yang terakhir di bidang mesin cuci LG menungguli Samsung dengan perolehan $17,00 \%$ sedangkan Samsung hanya mendapatkan 11,40\%. Dapat di lihat dari tabel diatas bahwa hampir semua produk LG unggul di banding Samsung, Samsung hanya bisa menungguli LG di bidang Home Theater.

Seperti pada penelitian yang dilakukan oleh $(\mathrm{H}$ Pasaribu, 2019) berdasarkan hasil analisis dan pembahasan menunjukan bahwa pemasaran yang terpadu berpengaruh dengan ekuitas merek, sedangkan citra merek tidak berpengaruh terhadap ekuitas merek dalam produk smart phone Samsung galaxy, lalu kualitas layanan berpengaruh terhadap ekuitas merek pada produk smartphone Samsung galaxy. Dalam kata lain penelitian tersebut menunjukan ekuitas merek berpengaruh signifikan terhadap komunikasi pemasaran terpadu dan kualitas pelayanan.

Sementara pada penelitian yang dilakukan oleh (Nasution, 2019) menunjukan bahwa ekuitas merek tidak berpengaruh terhadap loyalitas konsumen produk televisi LG, lalu kualitas produk tidak berpengaruh terhadap loyalitas konsumen LG, namun daya tarik iklan dapat mempengaruhi loyalitas konsumen produk televisi LG. Dalam penelitian ini ekuitas merek berpengaruh terhadap loyalitas konsumen televisi LG namun demikian daya tarik iklan yang mampu mempengaruhi loyalitas konsumen televisi LG.

Berdasarkan fenomena latar belakang yang sudah dijabarkan diatas maka penulis berminat untuk membuat sebuah penelitian. "Analisis Perbandingan Brand Equity LG dan SAMSUNG".

\section{Perumusan Masalah}

Berdasarkan pada latar belakang yang telah diuraikan diatas, maka perumusan masalah dalam penelitian ini yaitu: 1) Adakah perbedaan
Brand Association atau asosiasi merek di dalam merek LG dan Samsung? 2) Adakah perbedaan Brand Preceived Quality atau persepsi kualitas di dalam merek LG dan Samsung? 3) Adakah perbedaan Brand Loyalty atau loyalitas merek di dalam merek LG dan Samsung?

\section{Tujuan Penelitian}

Bedasarkan beberapa keterangan yang sudah dituliskan sebelumnya, maka tujuan penelitian ini yaitu untuk mengetahui seberapa besar perbedaan brand equity pada produk Samsung dan LG.

\section{Kegunaan Penelitian}

1. Manfaat Teoritis

Dapat memberikan wawasan serta informasi untuk pembaca serta berkontribusi memperkuat hasil penelitian yang telah dilaksanakan sebelumnya khususnya menyangkut Brand Equity atau ekuitas merek.

2. Manfaat Praktis

Membantu perusahan mengidentifikasi brand equity yang ada dimasyrakat pada saat ini, dan khususnya diwilayah Jakarta Selatan.

\section{TINJAUAN PUSTAKA \\ Merek}

Merek berasal dari kata Old Norse yang memiliki arti "membakar" yang pada dahulu kala digunakan peternak untuk menandai hewan ternaknya, namun sekarang menurut American Marketing Assiciation (AMA) merek adalah "istilah, nama, tanda, symbol, desain atau kombinasi" yang dimaksudnkan untuk mengidentifikasi barang atau jasa dari produk satu dengan yang lain (Keller, 2013 hlm 30), Merek adalah sebuah asset yang tidak mempunyai wujud tetapi memiliki peranan yang sangat penting bagi produsen, merek bukan hanya untuk membedakan produsen yang satu dengan yang lain melainkan merek juga sebagai isyarat informasi untuk sebuah value atau nilai yang dapat dirasakan dan dapat diperluas (Weindel, $2016 \mathrm{hlm} \mathrm{V}$ ), namun menurut (Firmansyah, 2019 hlm 26) berpendapat bahwa merek memiliki sebuah tujuan, dan dapat diurutkan 
sebagai berikut:

a. Membangun Kesadaran pada sebuah merek atau yang biasa disebut dengan Brand Awareness, merupakan sebuah kesadaran pelanggan yang dapat mengetahui dan mengingat merek, yang dimana akibat dari merek yang mendapatkan tempat perhatian dari pasar atau konsumen, dan merek akan dapat dipercaya.

b. Menciptakan kodisi emosional, yang dimana konsumen didalam membeli sebuah produk menggunakan atau berdasarkan atas sebuah perasaan atau emosional.

c. Membedakan Produk, yaitu pada saat konsumen sudah dapat memahami.

d. Mencipatakan Kredibilitas dan kepercayaan, yaitu merencanakan dan mengembangkan kredibilitas dan sebuah kepercayaan kepada merek.

e. Memotivasi Pembelian, yaitu sebagai alat pemasaran yang efektifi dan efisien dalam membangun sebuah minat, gengsi, motivasi, serta daya tarik sebuah pembelian bagi konsumen.

Berdasarkan pendapat dari para ahli diatas, maka dapat diketahui bahwa Merek didefinisikan sebagai pembeda dari produk yang satu dengan produk lainnya, serta sebagai asset yang tidak berwujud bagi perusahaan dikarenakan sifatnya yang sangat penting.

\section{Brand Equity}

Ekuitas merek merupakan sebuah value dari merek sebenarnya yang didapat melalui sebuah tindakan dan kata-kata dari konsumen. Hal ini bisa tercermin melalui cara seorang konsumen berfikir, merasakan, dan bertindak sehubungan dengan merek itu sendiri (Kotler \& Keller, 2016 hlm 324). Sedangkan menurut (Aaker et al., 2013) Berpendapat bahwa Ekuitas merek didefinisikan sebagai kumpulan asset dan kewajiban yang berkaitan dengan merek itu sendiri yang bertujuan untuk menambah maupun mengurangi dari nilai produk atau merek itu sendiri.

Ekuitas merek merupakan konsep yang dimana merek dianggap sebagai asset yang sejauh ini dapat dijual atau dibeli dengan harga, namun Merek yang dikatakan kuat adalah merek yang mempunyai ekuitas merek yang tinggi (Aaker et al., 2013 hlm 718). Namun menurut (Information Resources Management Association USA, 2019 hlm 184), Ekuitas merek atau brand equity tidak terlepas dari elemen-elemen pendukung dan elemen dalam membangun ekuitas merek seperti:
a. Brand awareness (kesadaran merek)
b. Brand loyalty (loyalitas merek)
c. Perceived quality (kesan kualitas)
d. Brand association (asosiasi merek)

Berdasarkan beberapa konsep diatas, dapat di sintesakan bahwa brand equity atau yang biasa disebut juga dengan ekuitas merek adalah sebuah kekuatan yang harus dimiliki oleh produsen agar mampu bersaing didalam kompetisi di dunia usaha.

\section{Brand Association}

Brand Association atau asosiasi merek adalah sebuah kekuatan, kesukaan, serta keunikan yang dapat dirasakan oleh konsumen, asosiasi merek dapat mewakili dalam sumber utama pada nilai merek, yang dikarenakan asosiasi merek merupakan sarana konsumen dalam merasa merek memenuhi kebutuhan mereka (Keller, $2013 \mathrm{hlm}$ 99). Namun menurut (Lee et al., 2015 hlm 91) berpendapat asosiasi merek merupakan segeala sesuatu yang terikat didalam ingatan terhadap sebuah merek, dan brand awareness sebagai dari sekumpulan asosiasi merek, asosiasi merek terhubung satu sama lain yang dapat terdiri dari beberapa ide, episode, contoh, serta fakta-fakta yang dapat membangun pengetahuan merek yang kuat.

Menurut (Putri \& Gede, 2018) Brand Association merupakan sebuah asosiasi merek yang kuat, dan dapat memberikan gambaran yang baik terhadap suatu merek. Namun demikian (Tjiptono Fandy, 2011 hlm 98) berpendapat bahwa "Brand Association merupakan segala sesuatu yang bersangkutan dengan memori terhadap suatu merek, brand association juga berkaitan dengan 
brand image yang dapat ditafsirkan serangkaian dari asosiasi merek dengan maksud tertentu".

Berdasarkan konsep diatas, dapat disintesakan bahwa asosiasi dan pencitraan,dapat mewakili sebagai sudut pandang yang dapat mencerminkan realita yang obyektif, dan merek yang telah mapan dapat mempunyai tempat yang menonjol dalam suatu kompetisi dikarenakan mendapatkan dukungan dari berbagai asosiasi yang kuat.

\section{Perceived Quality}

Perceived quality atau yang bisa disebut denga persepsi kualitas merupakan sebuah penilaian dari konsumen kepada keunggulan maupun superioritas yang dimiliki sebuah produk secara keseluruhan, Oleh karena itu persepsi kualitas adalah penilaian yang subyektif dari konsumen (Tjiptono Fandy, 2011 hlm 97). Namun menurut (Sangadji, Etta M. \& Sopiah., 2013 hlm 42) persepsi merupakan sebuah proses dalam setiap individu yang dimana mendpatkan, mengelola, mengorganisasi, dan menginterpretasikan informasi. Informasi yang sama apabila dipersepsikan oleh individu yang berbeda maka akan berbeda juga peresepsinya.

Menurut (Ayunir et al., 2019 hlm 9) Persepsi kualitas merupakan saah satu dari tugas perusahaan dalam membangun merek, peran dalam membangun persepsi kualitas yang tinggi harus mampu menaklukan konsumen di setiap kategori agar dapat di lirik oleh konsumen. Persepsi kualitas juga merupakan sebuah penilaian yang santun dan tidak bisa sama antar konsumen yang satu dengan konsumen lainnya. Persepsi kualitas yang baik mampu dibangun dengan mengidentifikasi dimensi kualitas yang menurut para konsumen itu sangat penting, dan membuat persepsi kualitas pada dimensi sangat penting pada sebuah merek. Konsumen bisa memiliki sikap terhadap suatu merek, akan tetapi yang paling utama ialah berhubungan dengan persepsi kualitas yang dirasakan dan nilai kepuasan pelanggan (Keller, $2013 \mathrm{hlm} \mathrm{177)}$
Namun kesan terhadap kualitas berbeda dengan kepuasan pelanggan, dimana kesan kualitas memiliki suatu perasaan yang tidak berwujud dan secara global mengenai sebuah merek (Aaker, 2017)

Berdasarkan konsep diatas, dapat disintesakan bahwa persepsi kualitas merupakan sebuah persepsi atau vista konsumen terhadap keseluruhan kualitas maupun kelebihan dari sebuah produk maupun jasa.

\section{Brand Loyalty}

Brand Loyalty atau yang disebut dengan loyalitas merek adalah sebuah keberadaan konsumen yang loyal terhadap sebuah merek yang merupakan bagian yang penting bagi sebuah perusahaan untuk mampu mempertahankan perusahaanya (Ayunir et al., 2019 hlm 9) Namun (Firmansyah, 2019 hlm 47) berpendapat bahwa loyalitas merek dapat didefinisikan sebagai suatu jenjang dimana konsumen mempunyai sebuah sikap yang positif kepada suatu merek, dengan memiliki komitmen dan kecenderungan didalam setiap melakukan pembelian selanjutnya.

Demikian (Aaker, 2017 hlm 56) loyalitas merek pelanggan adalah sebuah inti utama dari sebuah ekuitas merek, yang dimana para konsumen tidak tertarik kepada sebuah produk atau merek, dan kemudian melakukan pembelian karena adanya karakteristik didalam produk, harga, dan merasa nyaman ketika melakukan pembelian. Dengan demikian pelanggan atau konsumen dapat dengan mudah melakukan pembelian berulang dikemudia hari. Dengan ini loyalitas merek adalah sebuah konsep yang dimana itu sangat penting didalam strategi pemasaran, yang pada dasarnya keberadaan sebuah konsumen yang loyal kepada sebuah merek sangat di perlukan oleh perusahaan yang dapat membantu perusahaan dalam berkelangsungannya (Firmansyah, 2019 hlm 103).

Berdasarkan konsep diatas, dapat disintesakan bahwa Brand Loyalty adalah sebuah inti dari brand equity yang dimana komitmen kepada 
suatu merek dapat membuat perusahaan dapat bertahan.

\section{Hipotesis Penelitian}

Dalam penelitian ini memiliki hipotesis sebagai berikut:

H1 : Diduga terdapat perbedaan Brand Association secara signifikan antara Samsung dan LG

H2 : Diduga terdapat perbedaan Perceived Quality secara signifikan antara Samsung dan LG.

H3 : Diduga terdapat perbedaan Brand Loyalty secara signifikan antara Samsung dan LG.

\section{METODOLOGI}

\section{Teknik Pengumpulan Data}

1. Jenis dan Sumber Data

Menggunakan jenis data kuantitatif yang merupakan jenis data yang terjasi berupa angka ataupun numerik serta sumber data yang digunakan adalah sumber data primer yang didapat dari lapangan atau menggunakan penyebaran kuesioner yang dilakukan di daerah Jakarta Selatan, pada tahun 2021.

\section{Pengumpulan Data}

Peneliti melakukan pengumpulan data akan dilaksanakan dengan Teknik kuisioner yang dilaksanakan dengan cara meyebarkan sebuah kuisoner kepada responden bisa dalam bentuk cetak maupun online seperti google form.

1. Teknik Analisis Data dan Uji Hipotesis

Penelitian ini menggunakan data kuantitatif. Seluruh data yang sudah terkumpul dapat dianalisis dan kemudian dikakukan uji hipotesis. Prosedur yang akan dilakukan dalam menganalisis serta menguji hipotesis yaitu dengan Peneliti menggunkan jenis penelitian kuantitatif. Populasi pada penelitian ini yakni masyarakat diwilayah Jakarta Selatan yang sudah atau pernah menggunakan produk Samsung dan LG sebanyak 100 responden. Dengan menggunakan metode Likert dan tingkat sig. error sebesar 5\%. Pengambilan sampel pada penelitian ini dilakukan dengan menggunakan teknik non-probability sampling dan purposive sampling menjadi jenis sampel yang dilakukan dalam penelitian ini (Riyanto \& Hatmawan, 2020 hlm 12). Kriteria responden yakni adalah yang sudah atau pernah menggunakan produk Samsung dan LG. Teknik analisis data pada penelitian ini menggunakan uji syarat instrumen yaitu dengan menggunakan uji validitas dan uji reliabilitas, kemudian pengujian dilanjutkan memakai SPSS (Statistics Package for Social science), dan uji hipotesis dengan menggunakan uji Independent Sample T Test.

\section{HASIL DAN PEMBAHASAN}

Pada tabel diatas diinterpretasikan seluruh variable pertanyaan yang dimana menunjukan hasil yang diatas atau lebih besar dari $\mathrm{R}$ table $(0,361)$, yang dimana tingkat signifikansi $95 \%$. Dapat ditarik kesimpulan bahwa masing-masing indikator pertanyaan pada Samsung dan LG valid.

\section{Uji Reliabilitas}

Tabel 2. Hasil Uji Reliabilitas

\begin{tabular}{lcc}
\hline Samsung & Cronbach's Alpha & Keterangan \\
\hline Brand Association & 0,745 & Reliabel \\
\hline Perceived Quality & 0,872 & Reliabel \\
\hline Brand Loyalty & 0,906 & Reliabel \\
\hline LG & Cronbach's Alpha & Keterangan \\
\hline Brand Association & 0,742 & Reliabel \\
\hline Perceived Quality & 0,758 & Reliabel \\
\hline Brand Loyalty & 0,871 & Reliabel \\
\hline
\end{tabular}

Sumber : Hasil Output SPSS 26 yang diolah

Berdasarkan tabel diatas, hasil output Cronbach's Alpha menunjukan semua nilai Cronbach's Alpha diatas 0,7 yang dimana nilainya lebih besar dari 0,7 adalah reliabel. Maka variable brand association, perceived quality, dan brand loyalty Samsung dan LG dapat dinyatakan reliabel.

\section{Uji Independent Sample T Test}

Uji Independent Sample $T$ Test Brand Association

Berdasarkan dari tabel output group statistic brand association diatas diketahui jumlah data hasil brand association untuk brand association Samsung dan LG ada sebanyak 100 responden. Dengan nilai rata-rata hasil atau mean untuk 
Tabel 1. Uji Validitas

\begin{tabular}{|c|c|c|c|c|}
\hline & Pertanyaan & R Hitung & R Tabel & Keterangan \\
\hline & BA1SM & 0,699 & 0,361 & Valid \\
\hline & BA2SM & 0,81 & 0,361 & Valid \\
\hline & BA3SM & 0,514 & 0,361 & Valid \\
\hline & BA4SM & 0,82 & 0,361 & Valid \\
\hline & BA5SM & 0,601 & 0,361 & Valid \\
\hline \multirow[t]{7}{*}{ Validitas Brand Assiciation Samsung } & BA6SM & 0,666 & 0,361 & Valid \\
\hline & Pertanyaan & R Hitung & R Tabel & Keterangan \\
\hline & BA1L & 0,56 & 0,361 & Valid \\
\hline & BA2L & 0,872 & 0,361 & Valid \\
\hline & BA3L & 0,413 & 0,361 & Valid \\
\hline & BA4L & 0,666 & 0,361 & Valid \\
\hline & BA5L & 0,63 & 0,361 & Valid \\
\hline \multirow[t]{7}{*}{ Validitas Brand Association LG } & BA6L & 0,833 & 0,361 & Valid \\
\hline & Pertanyaan & R Hitung & R Tabel & Keterangan \\
\hline & PQ1SM & 0,768 & 0,361 & Valid \\
\hline & PQ2SM & 0,697 & 0,361 & Valid \\
\hline & PQ3SM & 0,586 & 0,361 & Valid \\
\hline & PQ4SM & 0,872 & 0,361 & Valid \\
\hline & PQ5SM & 0,885 & 0,361 & Valid \\
\hline \multirow[t]{7}{*}{ Validitas Perceived Quality Samsung } & PQ6SM & 0,871 & 0,361 & Valid \\
\hline & Pertanyaan & R Hitung & R Tabel & Keterangan \\
\hline & PQ1L & 0,488 & 0,361 & Valid \\
\hline & PQ2L & 0,812 & 0,361 & Valid \\
\hline & PQ3L & 0,532 & 0,361 & Valid \\
\hline & PQ4L & 0,715 & 0,361 & Valid \\
\hline & PQ5L & 0,765 & 0,361 & Valid \\
\hline \multirow[t]{5}{*}{ Validitas Perceived Quality LG } & PQ6L & 0,71 & 0,361 & Valid \\
\hline & Pertanyaan & R Hitung & R Tabel & Keterangan \\
\hline & BL1SM & 0,878 & 0,361 & Valid \\
\hline & BL2SM & 0,912 & 0,361 & Valid \\
\hline & BL3SM & 0,894 & 0,361 & Valid \\
\hline \multirow[t]{5}{*}{ Validitas Brand Loyalty Samsung } & BL4SM & 0,915 & 0,361 & Valid \\
\hline & Pertanyaan & R Hitung & R Tabel & Keterangan \\
\hline & BL1L & 0,877 & 0,361 & Valid \\
\hline & BL2L & 0,892 & 0,361 & Valid \\
\hline & BL3L & 0,867 & 0,361 & Valid \\
\hline Validitas Brand Loyalty LG & BL4L & 0,791 & 0,361 & Valid \\
\hline
\end{tabular}

Sumber : Hasil Output SPSS 26 yang diolah

Tabel 3. Hasil Uji Group Statistic Brand Association Group Statistics

\begin{tabular}{lccccc}
\hline & Merek & N & Mean & Std. Deviation & Std. Error Mean \\
\hline \multirow{2}{*}{ Brand Association } & Samsung & 100 & 25,92 & 3,384 &, 338 \\
\cline { 2 - 6 } & LG & 100 & 23,05 & 3,341 &, 334 \\
\hline
\end{tabular}

Sumber : Hasil Output SPSS 26 
brand association Samsung sebesar 25,92, sedangkan untuk brand association LG mendapatkan sebesar 23,06. Dengan ini secara deskriptif statistic dapat disimpulkan ada perbedaan rata-rata hasil brand association Samsung dengan LG.

Selanjutnya untuk menunjukan apakah perbedaan tersebut menggambarkan signifikan yang nyata atau tidak, untuk menafsirkan output tersebut maka perlu adanya Independent Sampel T Test berikut ini.

Berdasarkan output Independent Sampel $\mathrm{T}$ Tes brand association diatas bisa kita lihat bahwa dibagian Sig (2-tailed) atau probabilitas sebesar $0,000<0,05$, maka Sebagaimana dasar pengambilan keputusan dalam uji Independent $\mathrm{T}$ Test dapat disimpulkan bahwa HO ditolak dan Ha diterima, dengan demikian dapat disimpulkan bahwa adanya perbedaan yang signifikan atau nyata anatar rerata hasil brand association pada merek Samsung dengan LG.

\section{Uji Independent Sample $T$ Test Perceived Quality}

Berdasarkan dari tabel output group statistic Perceived Quality diatas diketahui jumlah data hasil Perceived Qualty untuk Perceived Qualty Samsung dan LG ada sebanyak 100 responden. Dengan nilai rata-rata hasil atau mean untuk Perceived Qualty Samsung sebesar 26,10 sedangkan untuk Perceived Qualty LG mendapatkan sebesar 23,53. Dengan ini secara deskriptif statistic dapat disimpulkan ada perbedaan rata-rata hasil perceived quality Samsung dengan LG.

Selanjutnya untuk menunjukan apakah perbedaan tersebut menggambarkan signifikan yang nyata atau tidak, untuk menafsirkan output tersebut maka perlu adanya Independent Sampel T Test berikut ini.

Berdasarkan output Independent Sampel $\mathrm{T}$ Tes perceived qualty diatas bisa kita lihat bahwa dibagian Sig (2-tailed) atau probabilitas sebesar 0,000 $<0,05$, maka Sebagaimana dasar pengambilan keputusan dalam uji Independent $\mathrm{T}$ Test dapat disimpulkan bahwa HO ditolak dan Ha diterima, dengan demikian dapat disimpulkan bahwa adanya perbedaan yang signifikan atau

Tabel 4. Output Uji Independent Sampel T Test Brand Association Independent Samples Test

\begin{tabular}{|c|c|c|c|}
\hline & & \multicolumn{2}{|c|}{ Brand Association } \\
\hline & & Equal variances assumed & Equal variances not assumed \\
\hline \multirow{2}{*}{ Levene's Test for Equality of Variances } & $\mathrm{F}$ &, 006 & \\
\hline & Sig. & ,939 & \\
\hline \multirow{7}{*}{ Levene's Test for Equality of Variances } & $\mathrm{t}$ & 6,036 & 6,036 \\
\hline & $\mathrm{df}$ & 198 & 197,968 \\
\hline & Sig. (2-tailed) &, 000 &, 000 \\
\hline & Mean Difference & 2,870 & 2,870 \\
\hline & Std. Error Difference & ,475 & ,475 \\
\hline & \multirow{2}{*}{$\begin{array}{l}95 \% \text { Confidence Interval } \\
\text { of the Difference }\end{array}$} & Lower & 1,932 \\
\hline & & Upper & 3,808 \\
\hline
\end{tabular}

Sumber : Hasil Output SPSS 26

Tabel 5. Hasil Uji Group Statistik Perceived Qualty Group Statistics

\begin{tabular}{lccccc}
\hline & Merek & N & Mean & Std. Deviation & Std. Error Mean \\
\hline \multirow{2}{*}{ Perceived Quality } & Samsung & 100 & 26,10 & 3,541 &, 354 \\
\cline { 2 - 6 } & LG & 100 & 23,52 & 3,500 &, 350 \\
\hline
\end{tabular}

Sumber : Hasil Output SPSS 26 
Tabel 6. Output Uji Independent Sample T Test Perceived Qualty Independent Samples Test

\begin{tabular}{|c|c|c|c|c|}
\hline & & \multicolumn{3}{|c|}{ Perceived Quality } \\
\hline & & Equal v & umed & Equal variances not assumed \\
\hline \multirow{2}{*}{ Levene's Test for Equality of Variances } & $\mathrm{F}$ & &, 001 & \\
\hline & Sig. & & 973 & \\
\hline \multirow{7}{*}{ t-test for Equality of Means } & $\mathrm{t}$ & & 5,182 & 5,182 \\
\hline & $\mathrm{df}$ & & 198 & 197,974 \\
\hline & Sig. (2-tailed) & & 000 & 000 \\
\hline & Mean Difference & & 2,580 & 2,580 \\
\hline & Std. Error Difference & & 498 & ,498 \\
\hline & \multirow{2}{*}{$\begin{array}{l}95 \% \text { Confidence Interval } \\
\text { of the Difference }\end{array}$} & Lower & 1,598 & 1,598 \\
\hline & & Upper & 3,562 & 3,562 \\
\hline
\end{tabular}

Sumber : Hasil Output SPSS 26

nyata anatar rerata hasil perceived quality pada merek Samsung dengan LG.

\section{Uji Independent Sample T Test Brand Loyalty}

Berdasarkan dari tabel output group statistic Brand Loyalty diatas diketahui jumlah data hasil Brand Loyalty untuk Brand Loyalty Samsung dan LG ada sebanyak 100 responden. Dengan nilai rata-rata hasil atau mean untuk Brand Loyalty Samsung sebesar 15,16 sedangkan untuk Brand
Loyalty LG mendapatkan sebesar 12,60. Dengan ini secara deskriptif statistic dapat disimpulkan ada perbedaan rata-rata hasil Brand Loyalty Samsung dengan LG.

Selanjutnya untuk menunjukan apakah perbedaan tersebut menggambarkan signifikan yang nyata atau tidak, untuk menafsirkan output tersebut maka perlu adanya Independent Sampel T Test berikut ini.

Tabel 7. Hasil Uji Group Statistik Brand Loyalty Group Statistics

\begin{tabular}{lccccc}
\hline & Merek & N & Mean & Std. Deviation & Std. Error Mean \\
\hline \multirow{2}{*}{ Brand Loyalty } & Samsung & 100 & 15,16 & 3,656 &, 366 \\
\cline { 2 - 6 } & LG & 100 & 12,60 & 3,624 &, 362 \\
\hline
\end{tabular}

Sumber : Hasil Output SPSS 26

Tabel 8. Output Uji Independent Sample T Test Brand Loyalty Independent Samples Test

\begin{tabular}{|c|c|c|c|c|}
\hline & & \multicolumn{3}{|c|}{ Perceived Quality } \\
\hline & & Equal & imed & Equal variances not assumed \\
\hline \multirow{2}{*}{ Levene's Test for Equality of Variances } & $\mathrm{F}$ & & 073 & \\
\hline & Sig. & & ,787 & \\
\hline \multirow{7}{*}{ t-test for Equality of Means } & $\mathrm{t}$ & & 4,973 & 4,973 \\
\hline & $\mathrm{df}$ & & 198 & 197,984 \\
\hline & Sig. (2-tailed) & & 000 & ,000 \\
\hline & Mean Difference & & 2,560 & 2,560 \\
\hline & Std. Error Difference & &, 515 &, 515 \\
\hline & \multirow{2}{*}{$\begin{array}{l}95 \% \text { Confidence Interval } \\
\text { of the Difference }\end{array}$} & Lower & 1,545 & 1,545 \\
\hline & & Upper & 3,575 & 3,575 \\
\hline
\end{tabular}

Sumber : Hasil Output SPSS 26 
Berdasarkan output Independent Sampel $\mathrm{T}$ Test Brand Loyalty diatas bisa kita lihat bahwa dibagian Sig (2-tailed) atau probabilitas sebesar $0,000<0,05$, maka Sebagaimana dasar pengambilan keputusan dalam uji Independent $\mathrm{T}$ Test dapat disimpulkan bahwa HO ditolak dan Ha diterima, dengan demikian dapat disimpulkan bahwa adanya perbedaan yang signifikan atau nyata anatar rerata hasil Brand Loyalty pada merek Samsung dengan LG.

\section{Pembahasan}

Berdasarkan output dari pengujian hipotesis dengan uji Independent Sample $\mathrm{T}$ Test yang menggunakan aplikasi IBM SPSS Statistik 26, diketahui bahwa ada perbedaan yang signifikan anatara Brand Equity Samsung dengan LG di Jakarta Selatan, hal tersebut dapat diketahui dari adanya penjelasan tiap-tiap indicator sebagai berikut:

1. Brand Association Produk Samsung dengan LG

Analisis perbandingan brand equity produk elektronik merek Samsung dengan LG pada kategori brand association diketahui memiliki perbedaan yang cukup signifikan, yang dapat kita lihat dari Table 3. Hasil Uji Group Statistic Brand Association berdasarkan dari hasil Independent Sample $\mathrm{T}$ Test Brand Association dapat dilihat bahwa Samsung lebih unggul dari pada LG. Hal tersebut diketahui dari hasil Mean atau rerata Brand Association yang dimana Samsung lebih unggul dari LG. Perbedaan ini terjadi dikarenakan Samsung selalu konsisten dalam pemenuhan permintaan pasar dan selalu memberikan harga yang lebih kompetitif dibandingkan dengan merek LG, serta Samsung selalu memberikan manfaat yang lebih bagi konsumennya.

Hal ini sejalan dengan (Aaker, 2017) yang menyatakan bahwa Asosiasi mampu memberikan sebuah nilai untuk suatu merek dari sudut pandang konsumen maupun produsen, asosiasi mampu menjadi pembeda pada suatu merek serta asosiasi merek mampu membangkitkan atribut kepada berbagai macam produk atau dapat bermanfaat bagi konsumen yang memberikan alasan yang spesifik untuk memutuskan untuk membeli dan menggunakan merek tersebut, dan memberikan perasaan yang positif ketika menggunakan atau pengalaman disaat menggunakan produk, Pernyataan tersebut sejalan dengan penelitian (Nainggolan, 2018) yang menyatakan Asosiasi merek berpengaruh signifikan terhadap Ekuitas merek.

2. Perceived Qualty Produk Samsung dengan LG

Analisis perbandingan Brand Equity produk elektronik Samsung dengan LG pada kategori Perceived Quality diketahui memiliki perbedaan yang cukup signifikan yang dapat kita lihat dari Tabel 5. Hasil Uji Group Statistic Perceived Quality berdasarkan dari hasil Uji Independent Sample $\mathrm{T}$ Test Perceived Quality dapat dilihat bahwa Samsung unggul dari pada LG. Hal tersebut diketahui dari hasil Mean atau rerata Perceived Quality yang dimana Samsung lebih unggul dari LG. Perbedaan ini terjadi dikarenakan dimata konsumen atau pengguna kualitas Samsung lebih baik, yang ditunjang oleh kinerja serta keandalan produk Samsung yang sangat baik dalam segala sector. Konsumen sudah mencoba berbagai macam brand electronic dan akhirnya mampu memberikan persepsi yang berbeda-beda terhadap brand yang satu dengan yang lainnya.

Hal ini sejalan dengan teori (Sangadji, Etta M. \& Sopiah., 2013) yang mengatakan bahwa Persepsi kualitas atau Perceived Quality Merupakan sebuah persepsi proses dalam setiap individu yang dimana mendapatkan, mengelola, mengorganisasikan, dan mengiterpretasikan sebuah informasi yang sama ketika di persepsikan oleh orang yang berbeda maka hasilnya juga berbeda, Sejalan dengan penelitian (Darmawan, Syarifah Hudayah, 2016) bahwa persepsi kualitas berpengaruh terhadap sebuah ekuitas merek.

3. Brand Loyalty Produk Samsung dengan LG Analisis perbandingan Brand Equity pada produk electronic Samsung dengan LG pada 
Brand Loyalty diketahui memiliki perbedaan yang cukup signifikan yang dapat kita lihat dari Tabel 7. Hasil Uji Group Statistic Brand Loyalty berdasarkan dari hasil Uji Independent Sampel $\mathrm{T}$ Test Brand Loyalty dapat dilihat bahwa Samsung unggul dari pada LG. Hal tersebut diketahui dari hasil mean atau rerata Brand Lotaly yang dimana Samsung lebih unggul dari LG. Perbedaan ini terjadi dikarankan Samsung mampu meberikan kepuasan pada konsumennya secara konsisten. Hal ini sejala dengan teori (Firmansyah, $2019 \mathrm{hlm} \mathrm{47)} \mathrm{yang} \mathrm{berpendapat}$ bahwa loyalitas merek dapat didefinisikan sebagai suatu jenjang dimana konsumen mempunyai sebuah sikap yang positif kepada sebuah merek, dengan memiliki komitmen dan kecenderungan didalam setiap melakukan pembelian selanjutnya. Sejalan dengan penelitian (Putra \& Aksari, 2018) ekuitas merek sangat berpengaruh signifikan terhadap loyalitas terhadap merek.

\section{SIMPULAN}

Berdasarkan dari hasil analisis data dan uraian bab pembahasan yang sudah dilakukan pada konsumen Samsung dan LG, maka penulis dapat menarik beberapa kesimpulan, yang dianatanya adalah:

a. Adanya perbedaan terhadap Brand Association anatar produk Samsung dengan LG. Dapat diketahui bahwa Samsung lebih baik dari pada LG, perbedaan tersebut dikarenakan Samsung selalu konsisten dalam pemenuhan permintaan pasar dan selalu memberikan harga yang lebih kompetitif dibandingkan dengan kompetitornya yaitu LG.

b. Adanya perbedaan terhadap Perceived Qualty antar produk Samsung dengan LG. Dapat diketahui bahwa Samsung lebih baik dari pada LG, perbedaan tersebut dikarenakan dimata konsumen atau pengguna kualitas Samsung lebih baik, yang ditunjang oleh kinerja serta keandalan produk Samsung yang sangat baik dalam segala sector.

c. Adanya perbedaan terhadap Brand Loyalty antar produk Samsung dengan LG. dapat diketahui bahwa Samsung lebih baik dari pada LG, perbedaan tersebut dikarenakan Samsung mampu meberikan kepuasan pada konsumennya secara konsisten dibandingkan produk LG.

Pada penelitian ini memiliki beberapa keterbatasan yang mungkin dapat menimbulkan gangguan terhadapa atau kepada hasil penelitian, diantaranya yaitu:

a. Terdapat beberapa toko elektronik yang tidak bisa memberikan data konsumennya.

b. Tehambatnya mobilitias disaat pencarian responden dikarenakan adanya PSBB.

c. Adanya responden yang rata-rata usia diatas 50 tahun memiliki keterbatasan untuk menjawab dikarenakan tidak mengerti cara mengisinya sehingga ada beberapa yang dibantu untuk diisikan oleh anak dari yang bersangkutan atau dibantu diarahkan oleh penulis.

d. Penelitian ini hanya menggunakan tiga variable independent yaitu, Brand Association, Perceived Quality, dan Brand Loyalty. Dikarenakan Brand Awerennes dari kedua merek tersebut sudah sangat tinggi atau Top of Mind.

\section{SARAN}

Berdasarkan hasil penelitian diatas dapat dikemukakan implikasi secara praktis sebagai berikut:

Hasil penelitian ini digunakan sebagai masukan bagi kedua perusahaan sebagai refrensi untuk memperkuat dari sisi merek tersebut, dengan memperhatikan Brand Equity. 


\section{DAFTAR PUSTAKA}

Aaker, D. A. (2017). Manajemen Ekuitas Merek: Memanfaatkan Nilai Dari Suatu Merek. Penerbit Mitra Utama.

Aaker, D. A., Kumar, V., Leone, R. P., \& Day, G. S. (2013). MARKETING RESEARCH (11th ed.). WILEY.

Ayunir, A. F., Erwinsyah, \& Sugeng, R. (2019). Analisis Perbandingan Keputusan Pembelian Produk MAKEUP Merek Wardah dan Maybelline Ditinjau dari Ekuitas Merek Pada Toko Redcanoeya Di Tenggarong. JEMI, 20.

Firmansyah, A. M. (2019). Pemasaran Produk dan Merek (Planning dan Strategy) (Qiara Media (ed.); 1st ed.). Qiara Media.

Information Resources Management Association USA. (2019). Brand Culture and Identity. In D. Mehdi Khosrow-Pour (Ed.), Brand Culture and Identity (Volume I). IGI Global. https://doi.org/ 10.4018/978-1-5225-7116-2

Jauhari, I. (2020). Pengaruh Diferensiasi Produk, Ekuitas Merek Dan Inovasi Produk Terhadap Keputusan Pembelian Produk Elektronik Korea Selatan. Jurnal Ilmiah Ekonomi Bisnis, 25(3), 226-237. https:/ /doi.org/10.35760/eb.2020.v25i3.2592

Keller, K. L. (2013). Strategic Brand Management (Stephanie Wall (ed.); 4th Editio). Pearson Education Limited. https://doi.org/10.2307/1252315

Kotler, P., \& Keller, K. L. (2016). Marketing Management 15th Global Edition. In England: Pearson Educationn Limited (15 Global). PEARSON. https://app.luminpdf.com/viewer/99cAGZGug6i5d4dsL

Lee, A., Yang, J., Mizerski, R., \& Lambert, C. (2015). The Strategy of Global Branding and Brand Equity. In The Strategy of Global Branding and Brand Equity (First). Routledge. https://doi.org/10.4324/9781315722528

Oktaviano, D. H. (2019, December). Kinerja Industri Elektronik Diprediksi Terus Naik. Bisnis.Com. https://ekonomi.bisnis.com/read/20191209/257/1179190/kinerja-industri-elektronikdiprediksi-terus-naik

Putri, V. D. A., \& Gede, S. G. I. K. A. G. (2018). Pengaruh Elemen Ekuitas Merek Terhadap Keputusan Pembelian Di Gerai Starbucks Coffe (Studi Pada Konsumen Domestik Starbucks Coffee di Wilayah Bali). E-Jurnal Manajemen Universitas Udayana, 7(1), 470. https://doi.org/10.24843/ejmunud.2018.v7.i01.p18

Riyanto, S., \& Hatmawan, A. A. (2020). Metode Riset Penelitian Kuantitatif Penelitian Di Bidang Manajemen, Teknik, Pendidikan Dan Eksperimen (1st ed.). Deepublish.

Sangadji, Etta M., \& Sopiah. (2013). Perilaku Konsumen Pendekatan Praktis. CV Andi Offset.

Tjiptono Fandy, P. . (2011). Manajemen \& Strategi Merek (01 ed.). ANDI Yogyakarta.

Weindel, J. K. (2016). Retail Brand Equity and Loyalty. In Retail Brand Equity and Loyalty. Springer Gabler. https://doi.org/10.1007/978-3-658-15037-2 